\title{
ARQUITECTOS E INGENIEROS MILITARES EN EL PALACIO REAL DE MÉXICO. PROYECTOS FALLIDOS PARA UN CUARTEL DE CABALLERÍA
}

(1761-1764)

\section{ARCHITECTS AND MILITARY ENGINEERS AT THE ROYAL PALACE OF MEXICO. FAILED PROJECTS FOR A CAVALRY BARRACKS (1761-1764) \\ Miguel Ángel Nieto Márquez ${ }^{1}$ Universidad de Sevilla \\ Orcid: 0000-0002-8337-5072}

Resumen: En 1761, el virrey marqués de Cruillas encomendó a Lorenzo Rodríguez el proyecto de ampliación del cuartel de caballería del Palacio Virreinal, si bien posteriormente los ingenieros militares Agustín López de la Cámara Alta y Pedro Ponce presentaron otras propuestas. Este estudio analiza detalladamente dichos proyectos, así como los motivos que llevaron a su suspensión.

Palabras clave: Arquitectura militar, maestros alarifes, Manuel de Santisteban.

\begin{abstract}
In 1761, the viceroy Cruillas entrusted Lorenzo Rodríguez the plan to expand the cavalry barracks in the Viceregal Palace, although later the military engineers Agustín López de la Cámara Alta and Pedro Ponce presented other proposals. This study analyzes these plans in detail, as well as the reasons for their suspension.
\end{abstract}

Keywords: Military architecture, master builders, Manuel de Santisteban.

\footnotetext{
${ }^{1}$ El presente artículo se inscribe en el desarrollo del proyecto de investigación I+D "PGC2018-099323-B-I00. Arquitecturas del poder en el Caribe y el Sudeste Asiático. 1729-1764", financiado por el Ministerio de Ciencia, Innovación y Universidades.
} 


\section{Introducción}

La importancia estratégica del virreinato de Nueva España durante el siglo XVIII hizo que los diferentes virreyes mostraran una especial atención a sus defensas y fortificaciones. ${ }^{2}$ La creación del Real Cuerpo de Ingenieros Militares en 1711 a propuesta del Jorge Próspero de Verboom llevó a estos profesionales a convertirse en una élite científica y cultural que no se limitó a las construcciones defensivas y militares, sino que además se encargó de infraestructuras y de obras de carácter civil, religioso, industrial o urbanístico ${ }^{3}$. Esto les ocasionó, tanto en la Península como en los territorios americanos, discrepancias y enfrentamientos con los arquitectos, quienes contaban con una formación diferente, extendiéndose esta polémica al siglo XIX. ${ }^{4}$ Ejemplos de estas controversias son los proyectos para la ampliación del cuartel de caballería del Palacio Real de México, unos planos conservados en el Archivo General de Indias (Sevilla) dados ya a conocer con un breve comentario por Angulo Íñiguez. ${ }^{5}$ A pesar de los largos trámites recogidos en el expediente de estas obras, ninguno de estos planes se llevó a cabo, al igual que ocurrió en numerosas ocasiones con otros proyectos. Con el presente trabajo se pretende profundizar en la polémica que existió en torno a estos cuarteles, así como analizar los distintos proyectos para comprender la diferencia de criterios entre arquitectos e ingenieros.

Entre las transformaciones producidas a raíz de la llegada de los Borbones a España, la modernización del ejército conllevó una especial atención al alojamiento de las tropas, buscándose su comodidad. Esto supuso un mayor bienestar en la población, ya que, hasta el momento, era la encargada de dar techo a estas milicias ante la ausencia de acuartelamientos. ${ }^{6}$ El modelo para levantar estas edificaciones fue el francés, muy conocido

\footnotetext{
${ }^{2}$ Ramón Gutiérrez, Fortificaciones en Iberoamérica. Madrid: Ediciones el Viso, 2005, p. 73.

${ }^{3}$ Jesús Cantera Montenegro, "Arquitectos e ingenieros: los ingenieros militares en el adelantamiento de la España ilustrada, en De la Paz de París a Trafalgar. La organización de la defensa de la monarquía. Madrid: Ministerio de Defensa. Instituto Español de Estudios Estratégicos, 2003, p. 25.

${ }^{4}$ Véase: Antonio Bonet Correa, Soledad Lorenzo Forniés y Fátima Miranda Recojo, La polémica de ingenieros-arquitectos en España, siglo XIX. Madrid: Colegio de Ingenieros de Caminos, Canales y Puertos, 1985.

${ }^{5}$ Diego Angulo Íñiguez, Planos de monumentos arquitectónicos de América y Filipinas conservados en el Archivo de Indias. Sevilla: Laboratorio de Arte, 1939, Estudio de los planos y de su documentación I, pp. 384386 y Catálogo II, láms. 129 y 130.

${ }^{6}$ Jesús Cantera Montenegro, La "Domus Militaris" hispana. Origen, evolución y función social del cuartel en España. Madrid: Ministerio de Defensa, 2007, p. 51. Sobre la vida en los cuarteles españoles durante el siglo XVIII, véase: José Omar Moncada Maya, "El cuartel como vivienda colectiva en España y sus posesiones durante el siglo XVIII" [En línea]. Scripta Nova: Revista electrónica de Geografía y Ciencias Sociales, N. ${ }^{\circ}$
} 
por la Corte y considerado el más avanzado, destacando la figura del marqués de Vauban como ingeniero a imitar, cuyas novedades, junto a las de Bernard Forest de Belidor, llegaron a España a través del Proyecto General Impreso de Verboom. ${ }^{7}$ Para sus proyectos, aparte de basarse en los conceptos arquitectónicos, los ingenieros militares también atendieron a aspectos sociológicos que vinieran a satisfacer las nuevas necesidades de la época. ${ }^{8}$

\section{El proyecto de Lorenzo Rodríguez}

Tras el motín de 1692, los antiguos cuarteles de caballería e infantería del Palacio Virreinal mandados construir por el Conde de Galve resultaban insuficientes para el alojamiento de las nuevas tropas. El cuartel de caballería se situaba entre la Cárcel de Corte y la casa del superintendente de la Casa de la Moneda. Al igual que el de infantería, la modesta dimensión del cuartel impedía la residencia de la tropa en su interior, por lo que el virrey marqués de Cruillas dispuso la construcción de un nuevo cuartel para soldados solteros y otro para casados sobre las caballerizas de la Compañía de Montados. ${ }^{9}$

La necesidad de ampliar el cuartel de caballería se reactivó en 1761, año en que el virrey ordenó su reconocimiento, a la vez que trató con el auditor de la guerra y juez de obras la posibilidad de emprender las correspondientes obras. ${ }^{10}$ Los planos fueron encargados a Lorenzo Rodríguez, quien tras la construcción del Sagrario Metropolitano entre 1749 y 1768 se había convertido en el arquitecto más importante de su época. El maestro los presentó el 10 de enero del mismo año junto a un presupuesto de 8.500 pesos, si bien no se ha localizado ningún documento donde se explique el proyecto. ${ }^{11}$ Desde su llegada a México en 1731, Rodríguez había desarrollado una amplia actividad, habiendo realizado las portadas del antiguo Colegio de las Vizcaínas y de la casa del conde Bartolomé de Xala, llevando a cabo

\footnotetext{
Extra 7, 146 (Barcelona, 2003). http://www.ub.edu/geocrit/sn/sn-146(007).htm [Consulta: 9 noviembre 2020]. ISSN: 1138-9788.

7 Cantera Montenegro, La "Domus militaris..., p. 51. Antonio Bonet Correa, "Utopía y realidad en la arquitectura”, en Manuel Serrano Marzo (Dir.). Domenico Scarlatti en España. Catálogo de la exposición. Madrid: Ministerio de Cultura, 1985, pp. 65-66

${ }^{8}$ Cantera Montenegro, La "Domus militaris..., p. 51.

${ }^{9}$ Efraín Castro Morales, Palacio Nacional de México. Historia de su arquitectura. México D. F.: Secretaría de Obras Públicas, 1976, p. 115.

${ }^{10}$ El virrey marqués de Cruillas a Julián de Arriaga. México, 9 de octubre de 1764. Archivo General de Indias (AGI), México, 2451.

${ }^{11}$ Angulo Íñiguez, op.cit., p. 384. Castro Morales, op.cit., p. 115.
} 
distintas intervenciones en el Colegio de Niñas, el Hospital Real de Naturales y en el mismo Palacio Virreinal. ${ }^{12}$

Lorenzo Rodríguez diseñó un cuartel de planta rectangular, separando a los soldados solteros, casados y oficiales (Figuras 1 y 2). En el plano señala en color amarillo lo ya existente y en encarnado lo que se proyectaba. ${ }^{13}$ Está dibujado a plumilla sobre papel, constando de dos hojas de 27 x $20 \mathrm{~cm}$. cada una, teniendo la segunda recortada la superficie correspondiente al hueco del patio, lo que permitiría leer el extenso título escrito en la primera en caso de superponerse. Incluye además una anotación que indica el norte y una escala gráfica de 10 varas. Su estado de conservación es deficiente.

\footnotetext{
${ }^{12}$ La bibliografía que ha tratado al arquitecto Lorenzo Rodríguez es extensa. Entre las obras más recientes, véase: Carlos Chanfón Olmos, Historia de la arquitectura y el urbanismo mexicanos. México: Fondo de Cultura Económica, 2005, vols. 2 y 3. Guillermo Tovar de Teresa, Repertorio de artistas en México. México: Grupo Financiero Bancomer, 1995. Joaquín Bérchez. Arquitectura mexicana de los siglos XVII y XVIII. México: Grupo Azabache, 1992. Mardith K. Schuetz-Miller, Architectural practice in México City. Tucson: Arizona University Press, 1987. Guillermo Tovar de Teresa, México Barroco. México: Secretaría de Asentamientos Humanos y Obras Públicas, 1981. Efraín Castro Morales, "Los maestros mayores de la Catedral de México". Artes de México, n. ${ }^{\circ} 182-183$ (México D.F., 1976), pp. 182 y ss.

${ }^{13}$ Testimonio de los autos para la ampliación del cuartel de caballería del Palacio Real de México. México, 1764, AGI, México, 1262, fol. 3r.
} 


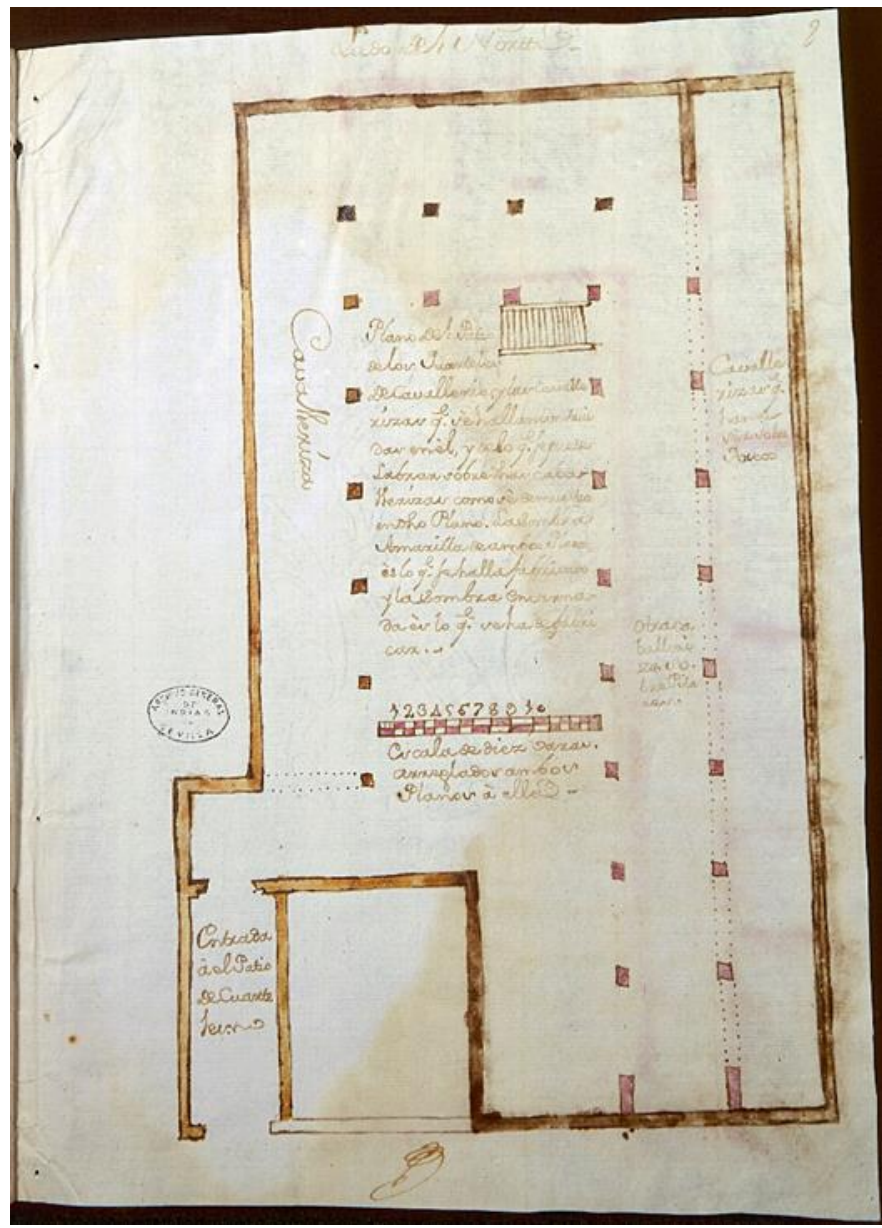

Figura 1. Lorenzo Rodríguez. Planta baja del proyecto de cuartel de caballería del Palacio Real de México, 1761.

El dibujo presenta algunas deficiencias en el trazado de las líneas, por haberse realizado a mano alzada. La entrada a los cuarteles se encontraría en el ángulo izquierdo del lado sur, accediéndose desde un zaguán a un patio donde se distribuirían las caballerizas. Como se ha indicado, en amarillo se dibujan los pilares de las caballerizas ya existentes al norte y al oeste, mientras que los dibujados en encarnado muestran la ampliación planteada por Rodríguez en los lados norte y este, proyectando dos galerías o naves en cada lado. Llama la atención que, a diferencia de lo diseñado en la parte norte, la segunda caballeriza del lado oriental se separa de la primera mediante una galería de arcos de fábrica, como bien se indica en la escritura del plano. Todos los pilares vendrían a sostener las dependencias planteadas en la segunda planta, a la que se accedería mediante una escalera situada al norte del patio. Una vez arriba, mediante un corredor descubierto en forma de "L", se llegaría a las diferentes estancias. Sobre las caballerizas originales de la zona occidental, se proyecta 
el nuevo "cuartel”, muy alargado e iluminado por cuatro ventanas, y en el área norte se distribuirían dos salas y tres recámaras, contándose con una sala más en la parte oriental. Desde ella y hasta el extremo sur del edificio, el corredor comunicaría con ocho cuartos prácticamente cuadrangulares, dispuestos sobre la galería de arcos proyectada en la planta baja. $^{14}$

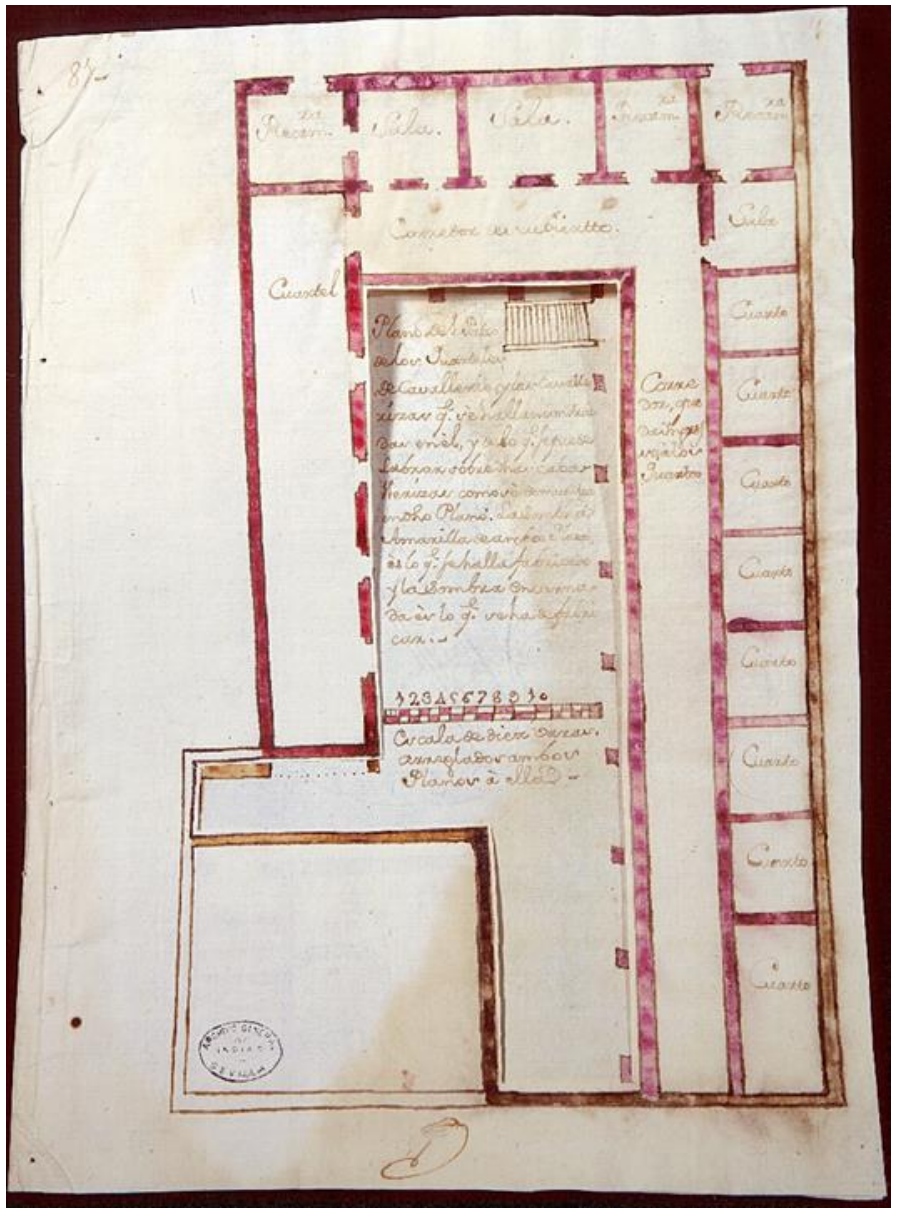

Figura 2. Lorenzo Rodríguez. Planta alta del proyecto de cuartel de caballería del Palacio Real de México, 1761.

La propuesta de Lorenzo Rodríguez venía a satisfacer las nuevas necesidades de las tropas, respetando en gran parte el modelo de cuartel que venía imponiéndose en el siglo XVIII. En este sentido, en 1680 Vauban había planteado un cuartel de planta rectangular en el que los soldados contaran con habitaciones, superando las tradicionales tiendas de

\footnotetext{
${ }^{14}$ Plano de las obras proyectadas para la ampliación del cuartel de la Compañía de Caballería del Real Palacio.
} México, 10 de enero de 1761, AGI, MP-México, 223BIS. 
campaña, quedando por tanto protegidos de las inclemencias meteorológicas. ${ }^{15}$ No obstante, aún se mantuvieron carencias en las condiciones de vida e higiénicas en los cuarteles, pues los soldados vivían hacinados debido a las limitaciones del terreno ${ }^{16}$. El maestro mayor Rodríguez asumió además las propuestas de Belidor al establecer las caballerizas en la planta inferior, estando los dormitorios y el resto de las dependencias en el piso alto. ${ }^{17}$ El patio, si bien no corresponde al modelo cuadrado que propuso este teórico en su obra La Science de l'Ingenieur dans la conduite des travaux de Fortification et d'Architecture (1729), posibilitaría la formación e instrucción, la entrada de los animales a sus caballerizas, daría una mayor funcionalidad al edificio y dotaría de luz a las distintas estancias ${ }^{18}$. Sin embargo, el patio fue uno de los puntos criticados de este sistema, ya que los contrarios a Belidor consideraron que impedía la circulación del aire, convirtiendo dicho espacio en un foco de humedad e infecciones, uniéndose a ello la creencia de que las escaleras, proyectadas en el patio, eran un vehículo de propagación de enfermedades por el segundo piso a través del pasillo que comunicaba las estancias ${ }^{19}$. Por otra parte, la necesidad de dar alojamiento a los caballos obligaba a que los cuarteles de caballería contaran con una mayor superficie que los de infantería, dándose también satisfacción a otros cometidos. ${ }^{20}$ Precisamente, esta fue una de las vicisitudes que ralentizó y frustró los proyectos en torno a este cuartel.

\section{La propuesta de Cámara Alta y Pedro Ponce. Discrepancias entre ingenieros y arquitectos}

Dos días después de que Rodríguez presentara los planos, el ingeniero en segundo Agustín López de la Cámara Alta advirtió que lo proyectado no se correspondía con el terreno real, pudiendo tener el Patio de la Pila - lugar donde se encontraba el cuartel -, capacidad para un escuadrón de caballería. ${ }^{21}$ Por ello, el 15 de enero de 1761, el virrey decretó que dicho ingeniero reconociera el plano del maestro mayor, insistiéndole en la

\footnotetext{
${ }^{15}$ Cantera Montenegro, “La Domus Militaris..., p. 54.

${ }^{16}$ Juan Marín y León, Acuartelamiento higiénico sistema Tollet. Madrid: Imprenta del Memorial de Ingenieros, 1880, p. 4.

${ }^{17}$ Cantera Montenegro, “La Domus Militaris..., p. 53.

${ }^{18}$ Ibídem. Amparo Marzal Martínez, "Los cuarteles andaluces del siglo XVIII". Revista de Historia Militar, n. 49 (Madrid, 1980), p. 36. José Antonio Sebastián Maestre, "Planimetría del cuartel español del siglo XIX. Anuario del Departamento de Historia y Teoría del Arte (UAM), vol. IV (Madrid, 1992), p. 262.

${ }^{19}$ Cantera Montenegro, “La Domus Militaris..., p. 54.

${ }^{20}$ Ibídem, p. 51.

${ }^{21}$ Angulo İñiguez, op.cit., p. 384. Castro Morales, Palacio Nacional de México..., p. 115
} 
importancia de la deseada ampliación, pues no había espacio para la cuarta parte de la compañía de caballería y debía evitarse la concesión de permisos para vivir fuera del palacio. ${ }^{22}$ Cámara Alta, destinado en Veracruz desde 1755, contaba con una gran trayectoria profesional. Al ser nombrado ingeniero en segundo, se encargó de las obras proyectadas para la defensa de la isla de Tris al mismo tiempo que debió seguir atendiendo las defensas del castillo de San Juan de Ulúa. ${ }^{23}$ Por otra parte, contaba con experiencia en la proyección de acuartelamientos, ya que tras la muerte del ingeniero Lorenzo de Solís en 1761, copió su proyecto de cuartel para el Regimiento de Infantería Fijo de la Corona, aunque añadiéndole una serie de modificaciones en el segundo piso. ${ }^{24}$

Cuando Cámara Alta visitó el cuartel existente, confirmó que no tenía capacidad para la cuarta parte de los soldados, señalando igualmente la falta de habitaciones para los tres oficiales subalternos. Así, el ingeniero realizó un nuevo plano para un proyecto más económico, ajustado a 8.000 pesos, presentándolo al mes siguiente. ${ }^{25} \mathrm{Al}$ considerarlo de "solidez y hermosura", ${ }^{26}$ se corrobora que, aunque en el siglo XVIII existió una mayor libertad de elección de los materiales, siempre se priorizó la firmeza, del mismo modo que se incidió en la adecuación a los principios de estética y armonía de las sobrias edificaciones castrenses. ${ }^{27}$ En la realización del plano intervino además el ingeniero Pedro Ponce, quien, desde su llegada a Veracruz en 1754 como criado de Carlos Luján, fue uno de los técnicos

\footnotetext{
${ }^{22}$ Testimonio de los autos para la ampliación del cuartel de caballería del Palacio Real de México. México, 1764, AGI, México, 1262, fol. 4v. y 5r.

${ }^{23}$ Sobre Agustín López de la Cámara Alta, véase: Horacio Capel y otros, Los ingenieros militares en España. Repertorio biográfico e inventario de su labor científica y espacial. Barcelona: Publications i Edicions de la Universitat de Barcelona, 1983, pp. 269-270. José Antonio Calderón Quijano, "Ingenieros militares en Nueva España". Anuario de Estudios Americanos, 6 (Sevilla, 1949), pp. 53-54. Carlos Moreno Amador, "El presidio y fuerte de Nuestra Señora del Carmen en la Laguna de Términos: la protección de Tabasco durante el siglo XVIII", en Pedro Cruz Freire e Ignacio J. López Hernández, Ingeniería e ingenieros en la América hispana. Siglos XVIII y XIX. Sevilla: Universidad de Sevilla, pp. 27-48.

${ }^{24}$ Angulo Íñiguez, op.cit., p. 381. Esta intervención de Cámara Alta en el proyecto de Solís también se menciona en: Patricia Ostante. Agustín López de la Cámara Alta. Descripción General de la Colonia del Nuevo Santander (Estudio preliminar, transcripción y notas). México: Universidad Nacional Autónoma de México, 2006, p. 25.

${ }^{25}$ Angulo Î́niguez, op.cit., p. 384. Castro Morales, Palacio Nacional de México... op.cit., p. 115.

${ }^{26}$ Testimonio de los autos para la ampliación del cuartel de caballería del Palacio Real de México. México, 1764, AGI, México, 1262, fol. 5r.

${ }^{27}$ Cantera Montenegro, "La Domus militaris..., p. 52.
} 
que intervino en más obras, ganándose la confianza de todos sus superiores por su labor intachable. $^{28}$

El plano (Figura 3), en un regular estado de conservación, cuenta con una escala de 20 varas, y está dibujado a plumilla sobre papel, iluminado a la aguada en marrón y encarnado. Su tamaño es de 30 x 40,5 cm. y el título se ubica en la parte superior, representándose la planta baja en la parte izquierda y el segundo piso en la parte derecha. La referencia a la autoría de Agustín López de la Cámara Alta aparece en el patio de la planta baja, mientras que la de Pedro Ponce se encuentra en el dibujo del piso superior. Al igual que en el proyecto anterior, estos ingenieros militares parecen haber realizado los planos a mano alzada y sin la ayuda de la escuadra y el cartabón, por lo que nuevamente se advierten deficiencias en el dibujo de los muros, pilares, arcos y escaleras. Lo mismo ocurre con las dependencias de la planta alta y con la pila del patio, cuyo irregular trazado pone de manifiesto la no utilización del compás y de los mencionados instrumentos.

${ }^{28}$ Sobre el ingeniero militar Pedro Ponce, véase: Calderón Quijano, op.cit., pp. 54-58. Capel y otros, op.cit., pp. 376-379. 


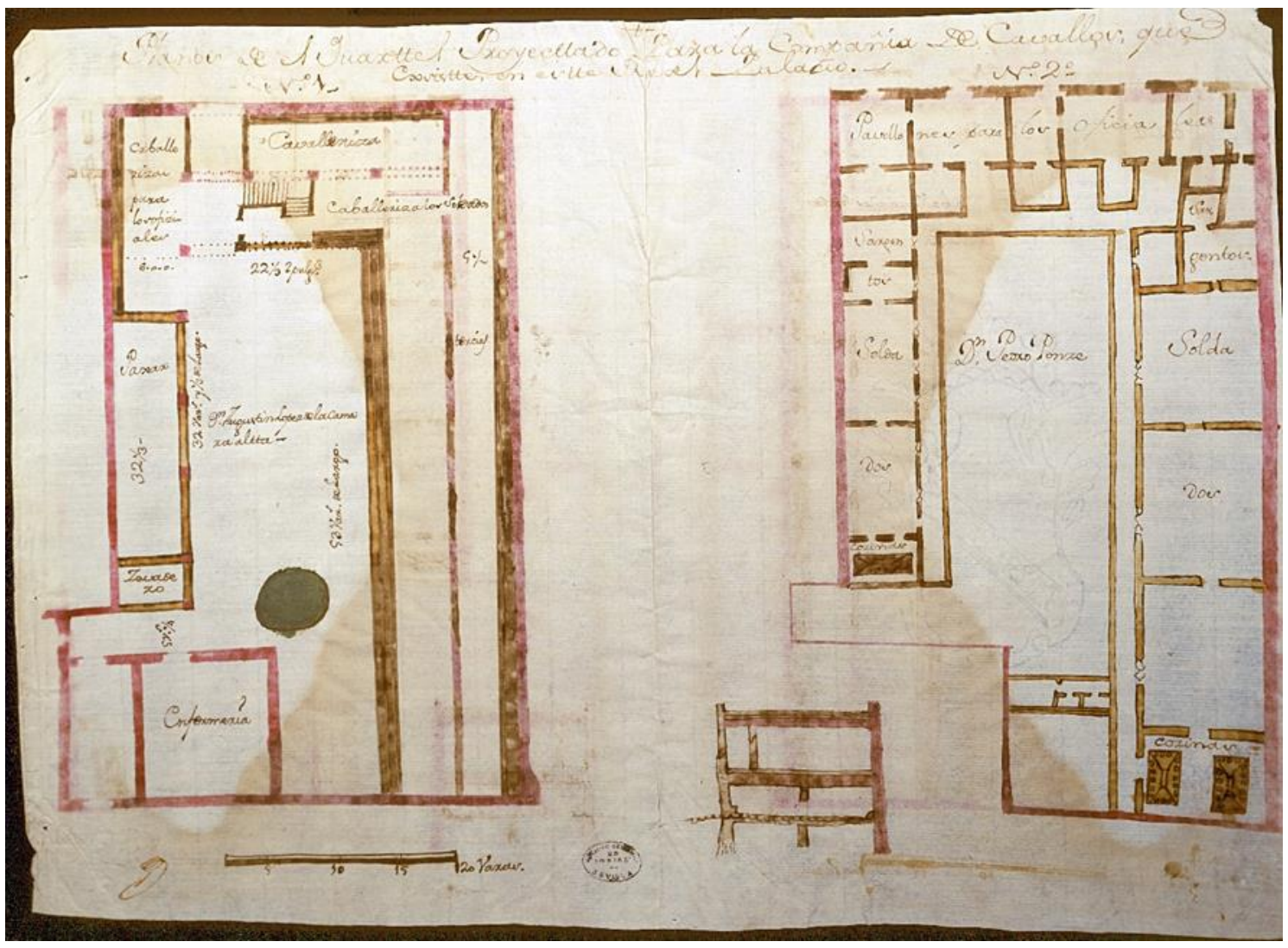

Figura 3. Agustín López de la Cámara Alta y Pedro Ponce. Proyecto de cuartel de caballería del Palacio Real de México, 1761.

La nueva propuesta de Cámara Alta pretendía que la tropa estuviera recogida a las horas que se indicaban en las ordenanzas, ${ }^{29}$ advirtiéndose en el plano un mayor conocimiento de las necesidades que tenía un cuartel de caballería en el siglo XVIII. De este modo, junto a la entrada se comprueba la inclusión de una enfermería, mientras que en el lado occidental planteaba un pajar alargado junto a un cebadero. En la parte norte distingue entre las caballerizas para oficiales, situadas en la izquierda, y las destinadas a los caballos de la tropa, que de igual forma que en el proyecto de Rodríguez se extendían longitudinalmente hasta el muro sur del cuartel. Como novedad, en la parte norte aparece otra entrada al cuartel entre las caballerizas de oficiales y de los soldados, algo que el maestro mayor no planteó, al igual que la pila del patio, representada en color negro. A diferencia del plano de Rodríguez, los ingenieros no dispusieron la escalera en el patio, probablemente por los aspectos sanitarios

${ }^{29}$ Testimonio de los autos para la ampliación del cuartel de caballería del Palacio Real de México. México, 1764, AGI, México, 1262, fol. 5r. y v. 
nocivos indicados anteriormente, ubicándola en el interior junto a la entrada, siendo de dos tramos en forma de "L" y con descansillo intermedio. En la planta superior, nuevamente comunicada por un corredor, distribuía los pabellones para oficiales, sargentos y soldados, contando los dos primeros con recámaras. En esta ocasión, el pasillo tendría forma de "U", posibilitando así la mayor separación de los alojamientos. Otra novedad que introducen los ingenieros son las cocinas, situadas en el extremo sur de cada lado, un aspecto criticado del modelo de Belidor, ya que se consideraba inapropiado que letrinas, cocinas y cuadras se encontraran ubicadas en el mismo bloque general del cuartel ${ }^{30}$. Cabe destacar también la minuciosidad de los ingenieros respecto a las medidas, que se aportan en el plano de la planta baja del cuartel.

Tanto el proyecto de Rodríguez como el de Cámara Alta fueron examinados por el auditor superintendente de la fábrica del palacio Domingo Valcárcel, quien manifestó que estos no coincidían ni en su modo de construcción ni en sus costos, verificando además la gran diferencia entre ambos al estar levantados en el mismo terreno y ser de diferentes tamaños. Por ello, Valcárcel propuso el nombramiento de dos peritos que fueran maestros de arquitectura de total crédito y confianza de la corte, quienes deberían supervisar las propuestas para tomar la resolución correspondiente. ${ }^{31}$ Los elegidos fueron los arquitectos Manuel Álvarez y Joaquín García de Torres, quienes dictaminaron que ambas eran incorrectas. $^{32}$

Manuel Álvarez fue maestro y alarife mayor de arquitectura en la ciudad de México, al igual que asentista de cañerías y acueductos ${ }^{33}$. Entre sus obras, destacan las Casas Reales de Tacuba (1759), ${ }^{34}$ siendo importante su participación en la elaboración de las ordenanzas de arquitectura del 7 de diciembre de 1735, al igual que en su nueva versión de $1746 .{ }^{35}$ En

\footnotetext{
30 "Plano del quartel proyectado para la compañía de Cavallos que existe en este Real Palacio". México, 4 de febrero de 1761, AGI, MP-México, 223TER. Cantera Montenegro, “La Domus Militaris..., pp. 53-54.

${ }^{31}$ Testimonio de los autos para la ampliación del cuartel de caballería del Palacio Real de México. México, 1764, AGI, México, 1262, fol. $5 \mathrm{v}$.

${ }^{32}$ Angulo Íñiguez, op.cit., p. 384. Castro Morales. Palacio Nacional de México..., p. 115.

${ }^{33}$ María Luisa Pazos y Catalina Pérez Salazar, Guía de las Actas de Cabildo de la ciudad de México: 17611770, siglo XVIII. México: Universidad Iberoamericana, 1988, p. 30.

${ }^{34}$ Chanfón Olmos, op.cit., p. 260.

35 Ana Eugenia Reyes y Cabañas, "Las ordenanzas de arquitectura de la ciudad de México de 1735". Boletín de Monumentos Históricos, Tercera época, 1 (México D. F., 2004), p. 41. Véase también: Stéphanie Migniot. "1736 y 1746. Dos proyectos para reformar el gremio de los albañiles de la ciudad de México. Nuevas hipótesis de interpretación”. Actas del III Congreso Internacional del Barroco americano: Territorio, Arte, Espacio y
} 
1737 se le encomendó como maestro mayor de la ciudad de México la realización del plano de la misma conservado en el Museo Nacional de Historia (Castillo de Chapultepec) junto a otros arquitectos como Pedro de Arrieta, y en 1740 estuvo en el jurado del examen de Lorenzo Rodríguez como veedor del gremio ${ }^{36}$. Por su parte, Joaquín García de Torres fue "maestro examinado en el arte de arquitectura" en 1743, y "maestro y veedor en el arte de la arquitectura y maestro del Juzgado de Capellanías y Obras Pías" del Arzobispado de México en 1762, un año después de estos episodios ${ }^{37}$. Trabajó en diversos avalúos, inspecciones y reedificaciones de inmuebles civiles y religiosos de la capital mexicana, al igual que para los conventos de San Jerónimo, La Enseñanza y La Concepción. ${ }^{38}$

El reconocimiento de estos maestros alarifes fue firmado el 14 de septiembre de 1761, volviendo a indicar la falta de correspondencia de los planos con las medidas reales del terreno. El plano del maestro mayor, según la escala en que lo realizó, presentaba un frente al que le faltaban 3 varas y media, mientras que en un ancón que formaba el terreno en el suroeste presentaba un ancho de 5 varas y una longitud de 4 varas menos. Además, consideraban que su fábrica no contaba con la solidez requerida, ya que los muros altos se apoyaban sobre planchas de madera, y no en arcos de piedra. ${ }^{39}$ Por ello, reiteraban la conveniencia de recurrir a estos, rechazando el aprovechamiento de los techos antiguos, que debían construirse nuevos y con maderas de mayor grosor. Por lo demás, los peritos indicaron que la caballeriza aumentada, que presentaba 60 varas de longitud, no contaba con

Sociedad. Universidad de Pablo de Olavide, Sevilla, 2001, p. 129. Natalia Silvia Prada. "Oficio y arte: Don Ildefonso de Iniesta Bejarano, un arquitecto novohispano, 1716-1781. Historia Mexicana. El Colegio Mexicano. Vol. 46, N. ${ }^{\circ} 2$ (México D. F., 1996), p. 290.

${ }^{36}$ Manuel Gustavo Revilla, Visión y sentido de la plástica mexicana. Edición, estudio introductorio y cronología de Elisa García Barragán. México: Universidad Autónoma Nacional de México, 2006, p. 116. Xavier Cortés Rocha. "El Examen de Maestría para el Ejercicio de la Arquitectura en los siglos XVI al XVIII en la Nueva España”, en Santiago Huerta Fernández, Paula Fuentes González e Ignacio Javier Gil Crespo (Eds.) Actas del Décimo Congreso Nacional y Segundo Congreso Internacional Hispanoamericano de Historia de la Construcción. Donostia-San Sebastián, 3-7 octubre de 2017, vol. 1, p. 343. José López Quintero, Maestros mayores de arquitectura de la Ciudad de México siglo XVIII (Tesis doctoral). México: Universidad Autónoma Nacional de México, 2006. Sobre el plano de la ciudad de México de 1737, véase: Francisco de la Maza y Luis Ortiz Macedo, Plano de la Ciudad de México de Pedro de Arrieta, 1737. México: Instituto de Investigaciones Estéticas, 2008.

${ }^{37}$ Glorinela González Franco, "El arquitecto Ildefonso de Iniesta Vejarano y Durán y su familia”. Boletín de Monumentos Históricos, Núm. 4 (México D. F., 2005), p. 65.

${ }^{38}$ Ibídem, p. 66.

39 Testimonio de los autos para la ampliación del cuartel de caballería del Palacio Real de México. México, 1764, AGI, México, 1262, fol. 6v. 7r. y v. Angulo Íñiguez. op.cit., p. 384. Castro Morales, Palacio Nacional de México..., p. 115. 
otras oficinas, mientras que, en la planta alta, sobre las caballerizas, Rodríguez planteaba tres viviendas "de dos piezas" para los oficiales subalternos y ocho cuartos para soldados. También censuraron la poca diferencia de tamaño de la "galera" o "cuartel" respecto a lo ya existente. $^{40}$

Respecto al plano de Cámara Alta, los maestros alarifes señalaron que, a pesar de presentar una demarcación y figura similar que la realizada por Lorenzo Rodríguez, no estaba realizado en la misma escala, por lo que las medidas parecían erróneas. Así, indican que las 60 varas del fondo realmente eran 55 y 3 cuartas, y que el ancón tenía 7 varas más de longitud, mientras que su ancho tenía 3 varas y 1 cuarta menos. Igualmente, de nuevo rechazaban el uso de planchas de maderas en detrimento de los arcos. Por otro lado, aunque los cuartos estaban planteados con amplitud, ocupando dos caballerizas, destacaban que para su ejecución habría que utilizar planchas de 12 varas de largo para sus techos en lugar de vigas, necesitándose además muros de mayor espesor. Con la introducción de un corredor la obra quedaría más firme y segura, quedando reducida al tamaño que ofrecía el terreno y manteniendo un coste de 8.500 pesos, habiendo aprovechado de la planta baja solamente los muros de los costados y de la calle. ${ }^{41}$

Una vez enterado de estas consideraciones, el virrey ordenó enviar el expediente a Agustín López de la Cámara Alta, quien en un informe fechado el 30 de septiembre señalaba que el terreno se adaptaba a la distribución del cuartel planteada. El 13 de octubre, añadió que, tras haber mandado medir la longitud del lado oriental, resultaban 53 varas de largo, y no las 53 y 3 cuartas que expresaban los alarifes. Del mismo modo, confesó que había descartado la utilización de arcos por falta de estribos, evitando de esta forma un mayor costo, considerando suficiente el uso de vigas para el piso principal sin perder la firmeza y solidez requeridas. Por tanto, alegaba que los arquitectos no habían comprendido su plano y que sus objeciones estaban mal fundadas, llegando a considerar que ningún maestro alarife podía "pretender dar Documentos ny proyectos de lo que no entienden, y mas si se les

\footnotetext{
${ }^{40}$ Testimonio de los autos para la ampliación del cuartel de caballería del Palacio Real de México. México, 1764, AGI, México, 1262, fol. 6v. 7r. y v.

41 Ibídem.
} 
pregunta la fuerza del Arco, de donde depende, sabiendo verdaderamente haverseles caido todas las bóvedas que han construido". ${ }^{42}$

El 6 de abril de 1762, el virrey ordenó que el expediente regresara al juez de palacio, reiterando la urgencia y la necesidad de ampliar el cuartel, ya que los soldados continuaban dispersos por la ciudad, faltando incluso a sus obligaciones. ${ }^{43}$ Domingo Valcárcel expuso que, con vistas al ahorro de la Real Hacienda en las obras, sería conveniente que el escribano acudiera cada día a supervisar el trabajo de los oficiales, incluido el último día de la semana, asistiendo también a los pagos. Dicha práctica era la habitual, al igual que la intervención de los mismos escribanos en la compra de materiales, velando por la economía de la Real Hacienda. Aun así, para mayor seguridad, el juez propuso que los citados arquitectos, Álvarez y Torres, ofrecieran todos los medios oportunos para dicho ahorro. ${ }^{44} \mathrm{~A}$ este respecto, el 30 de abril los maestros alarifes mostraban su inclinación por la ampliación del cuartel siguiendo el plano de Lorenzo Rodríguez, si bien se debía apostar por pilares y arcos de piedra de cantería y por la reducción a dos estancias grandes para el alojamiento de los soldados. La planta baja debería ser techada con maderas nuevas y de mayor grosor, manteniéndose el coste de toda la obra en 8.500 pesos. $^{45}$

Con la intención de elegir definitivamente el proyecto, durante una visita a Veracruz, el virrey marqués de Cruillas volvió a consultar el proyecto a los ingenieros Cámara Alta y Pedro Ponce, aprobando finalmente el realizado por el ingeniero militar. ${ }^{46}$ Estos consideraban que los proyectos de los maestros "no servían para nada", notándose que nunca habían diseñado cuarteles para la tropa, donde era importante diferencia las oficinas que eran precisas, así como repartirlas como correspondía. ${ }^{47}$ Ante este informe, el virrey volvió a enviar el expediente a Valcárcel para que lo enviara al Tribunal de Cuentas de cara al suministro de caudales para dicha obra. ${ }^{48}$ Valcárcel aprobó el dictamen de los dos ingenieros

\footnotetext{
42 Angulo Íñiguez, op.cit., p. 384. Castro Morales, Palacio Nacional de México..., p. 115. Testimonio de los autos para la ampliación del cuartel de caballería del Palacio Real de México. México, 1764, AGI, México, 1262, fol. 7v. y 8 r.

${ }^{43}$ Ibídem, fol. $8 \mathrm{r}$.

${ }^{44}$ Ibídem, fol. 8r. $-9 \mathrm{v}$.

${ }^{45}$ Ibídem, fol. 9v. y 10r. Angulo Íñiguez, op.cit., p. 385.

${ }^{46}$ Castro Morales, Palacio Nacional de México..., p. 115.

47 Testimonio de los autos para la ampliación del cuartel de caballería del Palacio Real de México. México, 1764, AGI, México, 1262, fol. 11r.

${ }^{48}$ Ibídem.
} 
a favor del proyecto de Cámara Alta por 8.000 pesos, ordenándosele al maestro mayor Lorenzo Rodríguez que se hiciera cargo de la obra. ${ }^{49}$ Este solicitó la colaboración de los arquitectos Manuel Álvarez y Joaquín de Torres para el "planteo y apertura de zanjas" y para la supervisión de las obras hasta su conclusión velando por el cumplimiento del proyecto, siendo aprobada la petición por Domingo Valcárcel el 9 de junio. ${ }^{50}$

Días más tarde, estando presentes en los cuarteles Rodríguez y los dos maestros alarifes, se le hizo saber al escribano que la inclusión de pilares y arcos de cantería unida al techado de los alojamientos de los soldados con vigas y tablas elevaría el coste de la obra a 3.000 pesos más debido a la escasez de operarios y materiales a causa de la epidemia que se estaba experimentando en ese momento. Del mismo modo advertían que en caso de no seguir estos requisitos, la obra no contaría con la estabilidad y la durabilidad pretendida, lo que llevó a Domingo Valcárcel a suspender la obra. ${ }^{51}$

\section{La intervención de Manuel de Santisteban y la suspensión definitiva del proyecto}

Hubo que esperar hasta 1764 para que nuevamente el virrey marqués de Cruillas reiterara la necesidad de reformar el cuartel ${ }^{52}$. Ante las discordias entre los criterios de ingenieros militares y los arquitectos, el fiscal Velarde consideró muy oportuno que Manuel de Santisteban, ingeniero director de las obras de fortificación de Veracruz, realizara un nuevo reconocimiento aprovechando que se encontraba en la ciudad. ${ }^{53}$ Santisteban fue uno de los ingenieros militares más renombrados de los que pasaron por Nueva España, debido al período de constante alarma bélica en el que desarrolló su actividad. ${ }^{54}$ Su destino se produjo el mismo año 1761, llegando a la plaza de Veracruz junto al también ingeniero Ricardo Aylmer. Aunque su principal misión fue el cuidado de las fortificaciones de dicha ciudad y su castillo, trazó otros proyectos, caso de un almacén de maderas junto a las

\footnotetext{
${ }^{49}$ Ibídem, fol. 12r. y v.

${ }^{50}$ Ibídem, fol. 12v. $-13 \mathrm{v}$.

${ }^{51}$ Ibídem, fol. 14r. y v.

Ibídem, fol. 15r.

${ }^{52}$ El virrey marqués de Cruillas a Julián de Arriaga. México, 9 de octubre de 1764, AGI, México, 2451.

${ }^{53}$ Testimonio de los autos para la ampliación del cuartel de caballería del Palacio Real de México. México, 1764, AGI, México, 1262, fol. 17r.

${ }^{54}$ Calderón Quijano, op.cit., p. 64.
} 
Atarazanas en $1764 .{ }^{55}$ Posteriormente trabajaría en la capital mexicana para poner remedio a la inundación de $1765,{ }^{56}$ y dos años después realizaría dos planos para el Hospital de San Joaquín, María y José de Veracruz, más tarde llamado de San Carlos. ${ }^{57}$ Sin duda, una de sus obras más destacables es el Fuerte de San Carlos de Perote, la cual dirigió hasta su finalización. ${ }^{58}$ En materia de cuarteles, realizó los planos para el que se había proyectado para defender el fondeadero de la punta de Antón Lisardo (Veracruz) en 1771, ${ }^{59}$ el mismo año en que realizó un mapa de una porción del Seno Mexicano. ${ }^{60}$

Santisteban reconocía que el aumento de los cuarteles del Palacio Real de México era una prioridad debido a "la estrechez" en que se encontraban entonces las tropas y sus caballos, la inexistencia de un lugar inmediato para los oficiales y los problemas de disciplina que todo ello acarreaba. ${ }^{61}$ El 26 de agosto de dicho año, dicho ingeniero director presentó los antiguos planos de Lorenzo Rodríguez con una serie de modificaciones que elevó el precio de la obra a 13.975 pesos. ${ }^{62}$ Para dotar la construcción de firmeza y duración, debería ejecutarse sobre pilares y arcos de sillería. De igual forma, señaló que los techos existentes no podrían reaprovecharse, al igual que subrayaba la baja calidad de la "muralla" paralela a la de la Casa de la Moneda, incapaz de mantener el tercer piso dispuesto en esa parte para los soldados, que también se levantaría sobre pilares y $\operatorname{arcos} .{ }^{63}$ En el frente opuesto proyectó

\footnotetext{
${ }^{55}$ Véase Pedro Torres Lanzas, Relación descriptiva de los mapas, planos, de México y Florida existentes en el Archivo General de Indias. Sevilla: Imprenta de el Mercantil, 1900, núm. 55. Angulo Íñiguez, op.cit., pp. 351352. Calderón Quijano, op.cit., p. 21.

${ }^{56}$ José Antonio Calderón Quijano, Historia de las fortificaciones en Nueva España. Madrid: Gobierno del Estado de Veracruz, CSIC, Escuela de Estudios Hispanoamericanos, 1984, p. 163.

57 Torres Lanzas, op.cit., núm. 236-237. Angulo Íñiguez, op.cit., p. 261-262. Sobre el Hospital de San Joaquín, María y José o San Carlos de Veracruz, véase: Josefina Muriel, Hospitales de la Nueva España, Tomo II. Fundaciones de los Siglos XVII y XVIII. México: Universidad Nacional Autónoma de México, Cruz Roja Mexicana, 1991, pp. 258-268.

${ }^{58}$ Calderón Quijano, "Ingenieros militares..., p. 67.

${ }^{59}$ Capel y otros, op.cit., t. IV, p. 441

60 José Omar Moncada Maya, "Las defensas de Veracruz en 1783, según la Relación del ingeniero Miguel del Corral". Biblio 3W. Revista Bibliográfica de Geografía y Ciencias Sociales, vol. VIII, n. 456, (Barcelona, 2003).

${ }^{61}$ Testimonio de los autos para la ampliación del cuartel de caballería del Palacio Real de México. México, 1764, AGI, México, 1262, fol. 17r. y v.

${ }^{62}$ Angulo Íñiguez, op.cit., p. 385. Castro Morales, Palacio Nacional de México..., p. 115.

"Plano del quartel proyectado para la Compañía de Cavalleria y sus oficiales existentes en este Real Palacio y que por falta de aloxamiento se halla esta tropa en la mayor incomodidad". México, 23 de agosto de 1764, AGI, MP-México, 223.

${ }^{63}$ La inclusión de una tercera planta en los cuarteles ya la recogió el mariscal Jorge Próspero Verboom en su normativa de 1717, buscándose así conseguir más alojamientos para oficiales. Dicha normativa fue firmada en Barcelona, bajo el nombre de Esplicacion para servir de instrucción a la fabrica de Cuarteles para las Tropas del Rey, así de Ynfanteria como de Cavalleria, que por regla general se pueden construir en las plazas de
} 
levantar un segundo piso para la tropa, así como las habitaciones para tres oficiales "en el que forma la calle Arzobispal siguiendo un corredor descubierto en ese lado, y el citado de la casa de la Moneda". 64

La relación del maestro mayor, fechada el 27 de agosto, detalla los diferentes gastos de este proyecto: ${ }^{65}$

\begin{tabular}{|c|c|}
\hline \multicolumn{2}{|c|}{$\begin{array}{l}\text { Cálculo prudencial del aumento proyectado en el Cuartel de Caballería del Real Palacio } \\
\text { (Lorenzo Rodríguez, 27/08/1764) }\end{array}$} \\
\hline Obra & Coste (Pesos, reales) \\
\hline Arquería y pilares & 3.960 \\
\hline Hoja de mampostería unida a la pared de la Casa de la Moneda & 725 \\
\hline Paredes maestras en mampostería de tezontle & 2.820 \\
\hline $\begin{array}{l}\text { Pared maestra en el tercer cuerpo y en el lado de la Casa de la Moneda hasta } \\
\qquad \text { el enladrillado de su azotea }\end{array}$ & 687 \\
\hline $\begin{array}{l}\text { Tabiques de separación de viviendas de los oficiales en el lado del } \\
\text { Arzobispado }\end{array}$ & 260 \\
\hline Cimientos y pilotaje & 296 \\
\hline Puertas y ventanas en madera de cedro & 540 \\
\hline 6 rejas de hierro exteriores & 235 \\
\hline Antepechos para los techos de las caballerizas & 3.880 \\
\hline Vigas & 62,5 \\
\hline 2 escaleras & 250 \\
\hline Pesebreras forradas de madera & 260 \\
\hline
\end{tabular}

Guerra y otros parajes de este Reyno, donde se pone guarnición o tropas en Cuartel. Cantera Montenegro, "La Domus militaris..., pp. 57-58

${ }^{64}$ Testimonio de los autos para la ampliación del cuartel de caballería del Palacio Real de México. México, 1764, AGI, México, 1262, fol. 17r. y v.

${ }^{65}$ Ibídem, fol. 15r. y 16 r. 
A diferencia de los anteriores, este plano se conserva en buen estado (Figura 4 y 5). Dibujado a plumilla en tinta negra sobre papel, está iluminado en amarillo y encarnado para distinguir lo construido de lo proyectado según se señala en una anotación. Está formado por dos hojas sueltas de 23,5 x 41 y 16,8 y 22,5 cm., contando al igual que los dos predecesores con escala, en esta ocasión de 30 varas. En la hoja correspondiente a la planta baja, el título se encuentra en la parte izquierda, seguido de una explicación en clave alfabética de los puntos marcados en el plano, apareciendo al final la fecha, 23 de agosto de 1764, y la firma de Lorenzo Rodríguez. Desde el punto de vista técnico, se refleja la condición de ingeniero director de Manuel de Santisteban, sirviéndose de escuadra y cartabón para el trazado del plano, como se aprecia en la representación de los muros y de los arcos. Igualmente, las escaleras fueron realizadas con la ayuda de estos instrumentos de medición, al igual que la circunferencia de la pila, donde se evidencia la utilización del compás.

Al igual que en la propuesta de Cámara Alta y Pedro Ponce, el cuartel cuenta con dos entradas, una al norte junto a las caballerizas, y otra al sur que da acceso directamente al patio. Se respetan las ampliaciones de las caballerizas planteadas originalmente por Rodríguez (B), al igual que la posición de la escalera en el patio, si bien en esta ocasión se representa la pila, que también fue incluida en los planos de Cámara Alta y Ponce. Como se comprueba en el dibujo, se apuesta definitivamente por el sistema de arcos sobre pilares para asegurar la estabilidad del edificio, lográndose una apariencia de patio porticado. En la segunda planta, el corredor descubierto original en forma de "L" da acceso a las nuevas habitaciones para soldados en el lado occidental (D), a los tres alojamientos proyectados para oficiales con sus recámaras y a las habitaciones ya existentes de los soldados en el ala oriental (C). Al tercer piso se accedería por unas segundas escaleras situadas entre dichas habitaciones y el alojamiento más oriental de los oficiales. Se lograría así la capacidad deseada para dicho cuartel, aspecto que no terminaba de solventar la propuesta de Cámara Alta.

Así pues, se observa cómo Santisteban se limitó a mejorar el proyecto de Rodríguez valiéndose de algunas propuestas de los otros dos ingenieros, intentando solventar la polémica existente sobre las medidas y el tamaño del cuartel. Igualmente, se constata la intención del ingeniero director de otorgar una mayor consistencia y funcionalidad a la idea 
original del maestro mayor, destacando la inclusión de una segunda entrada y de la citada tercera planta. A pesar de todo, aunque en octubre del mismo año el marqués de Cruillas solicitó autorización para edificar el cuartel, esta nunca llegó. Finalmente, la obra se redujo solamente a algunas reparaciones menores por 80 pesos, designando a este local como Cuartel de Dragones. ${ }^{66}$

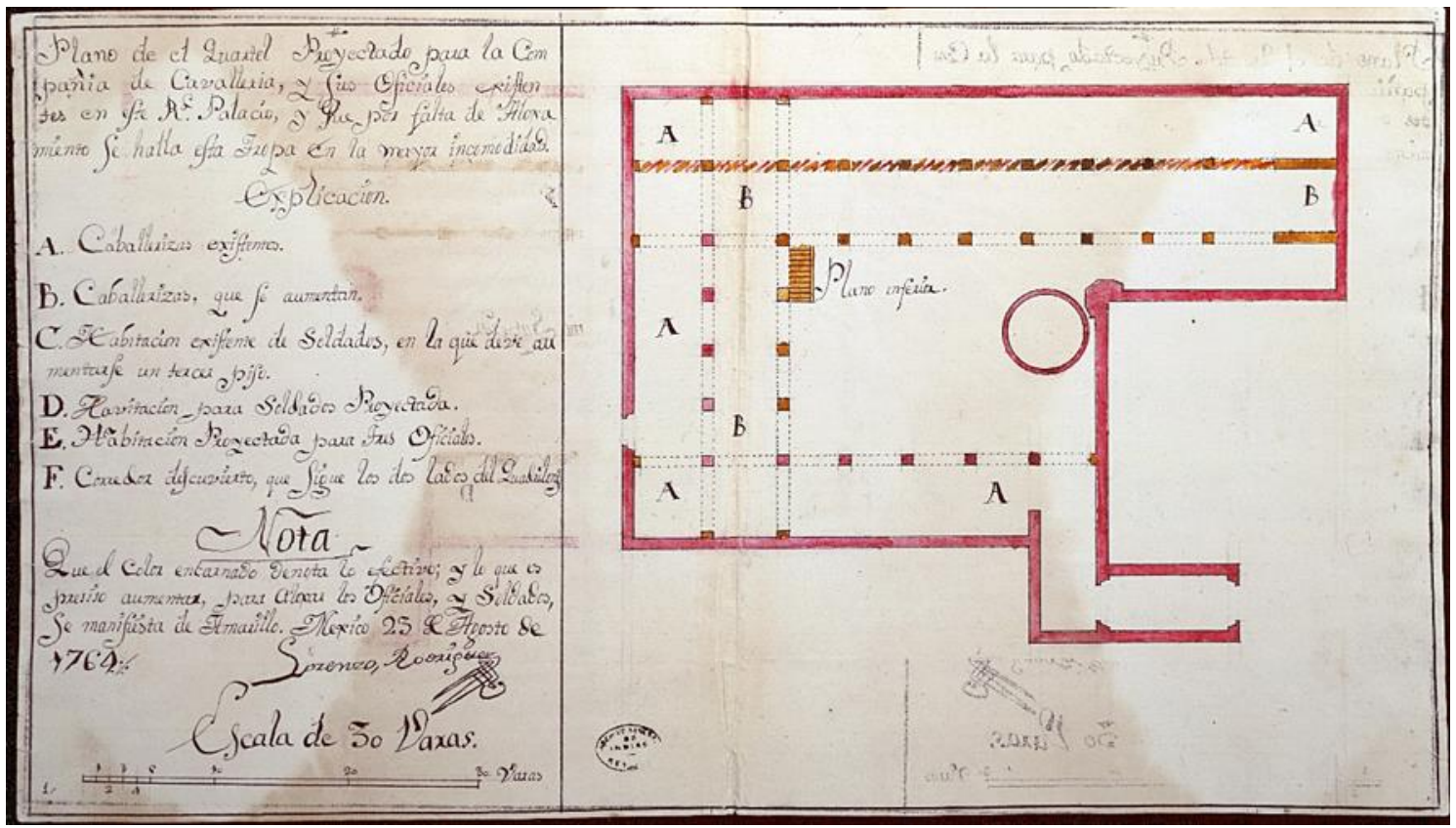

Figura 4. Lorenzo Rodríguez y Manuel de Santisteban. Planta baja del proyecto de cuartel de caballería del Palacio Real de México, 1764.

${ }^{66}$ Castro Morales, Palacio Nacional de México..., p. 115. 


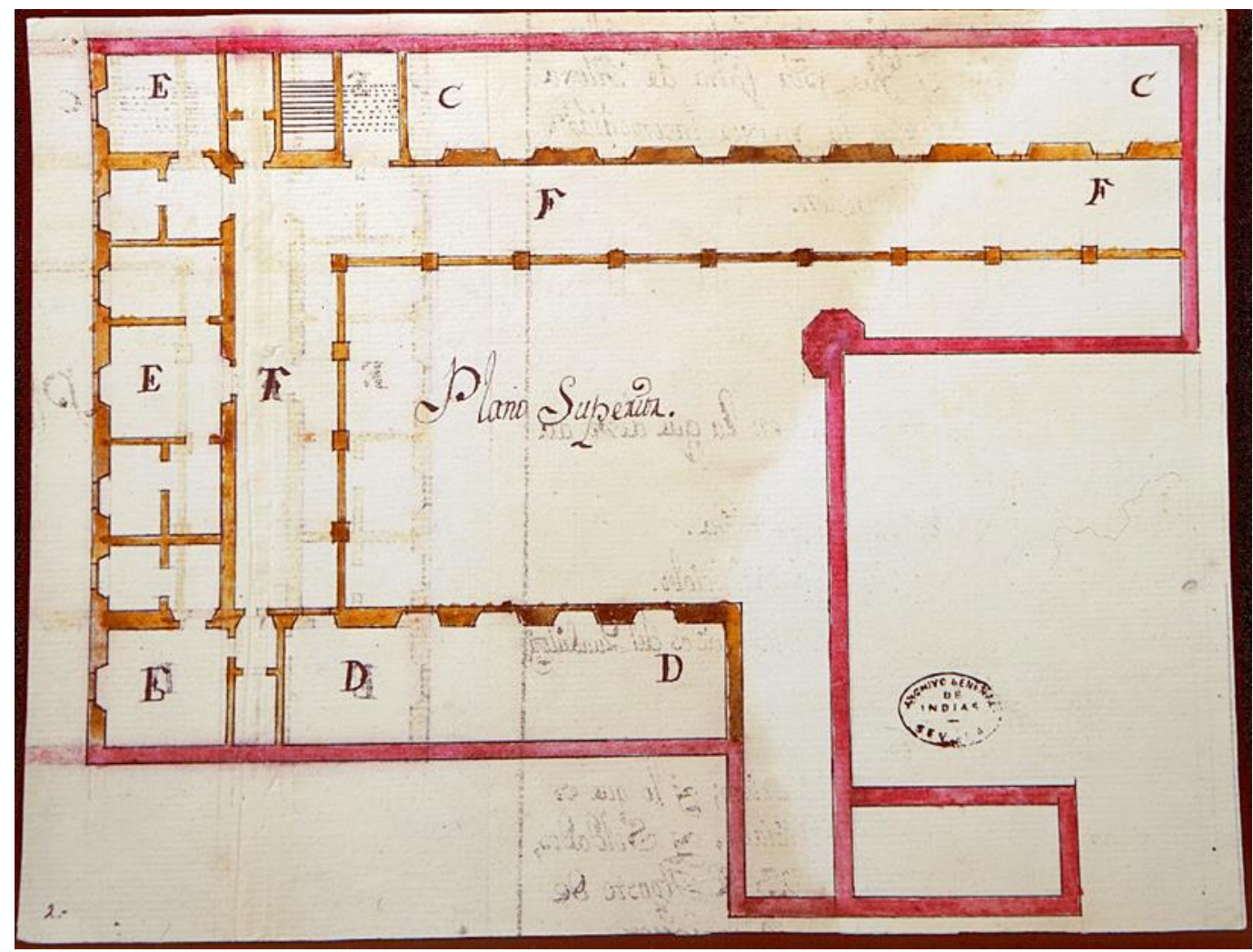

Figura 5. Lorenzo Rodríguez y Manuel de Santisteban. Planta alta del proyecto de cuartel de caballería del Palacio Real de México, 1764.

\section{Conclusión}

El presente estudio confirma la controvertida relación profesional que existió entre los arquitectos y los ingenieros militares hasta bien entrado el siglo XIX. Como se ha puesto de manifiesto en estudios previos, el aumento de competencias experimentado por los ingenieros militares dio lugar a una serie de discrepancias con los arquitectos y maestros de obras, siendo prueba de ello los proyectos que se analizan en el presente artículo. De esta forma, aunque en el proyecto original de Lorenzo Rodríguez parecen tenerse en cuenta los modelos dieciochescos basados en los preceptos de Vauban y Belidor, los ingenieros militares ofrecieron una alternativa más sólida, funcional y acorde con las necesidades de la tropa. Además, llama la atención cómo Cámara Alta se refiere a la "hermosura" del edificio, probablemente fruto del interés de estos profesionales por dotar a sus arquitecturas de una imagen acorde con el poder. No obstante, las fuertes desavenencias entre ingenieros y arquitectos provocaron la suspensión de las obras hasta la intervención del ingeniero director 
Manuel de Santisteban, quien retoma la idea de Rodríguez, aunque introduciendo algunas modificaciones de acuerdo con sus consideraciones técnicas. A pesar de ello, estos cuarteles se unen a una larga lista de proyectos frustrados, ya que la labor ingenieril estuvo condicionada frecuentemente por la situación política y económica. En el caso de los cuarteles de caballería, las restricciones económicas dictadas por la Real Orden de 1 de octubre de 1721 abortaron las buenas intenciones planteadas por Verboom en su normativa de 1717 , enfocadas al aumento de su capacidad. ${ }^{67}$ Por tanto, la suspensión de proyectos como los analizados en este artículo obligó a la sociedad civil a continuar dando alojamiento a los soldados, una situación que se mantuvo a pesar de lo indicado en el Real Cuerpo. ${ }^{68}$

${ }^{67}$ Cantera Montenegro, "La Domus militaris..., p. 67. Joseph Antonio Portugués. Colección General de las Ordenanzas Militares, sus innovaciones, y aditamentos, dispuesta en diez tomos, con separación de clases, tomo II. Madrid: Imprenta de Antonio Marín, 1764, pp. 551-556.

${ }^{68}$ Cantera Montenegro, "La Domus militaris..., p. 52. 